\title{
MNEMONIK : SOLUSI KREATIF UNTUK MENINGKATKAN KEMAMPUAN MENGHAFAL KOSA KATA BAHASA ARAB SISWI MADRASAH ALIYAH NURUL JADID
}

\author{
Sulton Firdaus \& Siti Hafidah \\ Universitas Nurul Jadid Paiton Probolinggo \\ sultonfirdaus@unuja.ac.id, sitihafidah97@gmail.com
}

\begin{abstract}
This study aims to determine the process of learning Arabic vocabulary with several methods in the class, and how teachers deal with these obstacles. There needs to be a breakthrough for teachers to be more creative in choosing alternative methods, the methods used by teachersin Madrasah Aliyah Nurul Jadid to make it easier for students to improve their memory in memorizing Arabic vocabulary. In its application is to use mnemonic techniques including those that are often used, namely association and rhyme. This research is a descriptive study with a qualitative approach, data collection techniques that researchers do by observation and interviews, the results of this study indicate: First, the application of Arabic vocabulary learning using the association and rhyme method runs well and smoothly, the learning process becoms more fun, can foster student enthusiasm, thus it can be concluded that the teaching of vocabulary using these methods proved effective for improving student learning outcomes Madrasah Aliyah Nurul Jadid.
\end{abstract}

Keywords : Mnemonic, Memorising Skill, Arabic Language.

\begin{abstract}
Abstrak: Penelitian ini bertujuan untuk mengetahui proses pembelajaran Kosa kata bahasa arab dengan beberapa metode di kelas, dan bagaimana cara guru dalam menghadapi kendala tersebut. perlu adanya terobosan guru untuk lebih kreatif dalam memilih metode yang menarik serta menyenangkan untuk di pelajari. Mnemonik adalah salah satu solusi kreatif, metode yang di gunakan guru di Madrasah Aliyah Nurul Jadid untuk mempermudah bagi para siswi dalam meningkatkan daya ingat menghafal kosa kata bahasa Arab. dalam penerapannya ialah dengan menggunakan teknik-teknik mnemonik diantaranya yang sering di pakai yaitu asosiasi dan rima. Penelitian ini merupakan penelitian deskriptif dengan pendekatan kualitatif. teknik pengumpulan data yang di lakukan peneliti ialah dengan observasi dan wawancara. Hasil penelitian ini menunjukkan : Penerapan pembelajaran kosa kata bahasa arab menggunakan metode asosiasi teknik cerita dan rima berjalan dengan baik dan lancar, proses pembelajaran menjadi lebih menyenangkan, dapat menumbuhkan antusias siswa, Dengan demikian dapat disimpulkan bahwa pengajaran kosa kata bahasa arab dengan menggunakan metode tersebut terbukti efektif untuk meningkatkan hasil Belajar siswa Madrasah Aliyah Nurul Jadid.
\end{abstract}

Kata Kunci : Mnemonik, Kemampuan Menghafal, Bahasa Arab 


\section{PENDAHULUAN}

Arabic Language atau biasa disebut dengan bahasa Arab merupakan salah satu mata pelajaran bahasa internasional dan termasuk bahasa importance (penting) untuk di kaji dalam pendidikan formal maupun non-formal ${ }^{1}$. Namun dalam mempelajari bahasa tersebut tentunya tidak mudah, banyak kosa kata (mufradat) yang sulit dimengerti oleh para siswi. Hal ini dikarenakan guru kurang memahami metode pembelajaran yang baik, dan kurang inovatif saat mengajar².

Hasil riset menunjukkan dari beberapa lapangan sekolah bahwasannya seorang guru saat mengajar cenderung memakai metode yang rumit, pembelajaran yang menoton, pengajaran yang kurang telaten, dan juga media yang kurang memadai ${ }^{3}$ Sehingga banyak para siswi yang kurang berantusias saat belajar bahkan tidak menyukai pembelajaran bahasa Arab di karenakan sulitnya menghafal kosa kata bahasa tersebut. Pada akhirnya ketika pembelajaran berlangsung menjadi tidak efektif dan banyaknya para siswi mengantuk dan berbicara sendiri saat di kelas ${ }^{4}$.

Hal ini sangatlah penting untuk diperhatikan mengingat, tujuan pembelajaran bahasa Arab sebagaimana di tegaskan dalam lampiran Permendiknas no: 22 tahun 2006 tentang standar isi ${ }^{5}$ ialah membuat peserta didik memiliki kemampuan dasar dalam empat keterampilan maharah : (maharah istima'), (syafany kalam), (qiro'ah), dan(kitabah) dalam berkomunikasi secara sederhana dan saling melengkapi ${ }^{6}$.

Apalagi melihat masa kini memahami bahasa Arab menjadi sebuah kebutuhan dimana, dengan perkembangan zaman kemajuan teknologi dan komunikasi

\footnotetext{
${ }^{1}$ M. Ngalim Purwanto, Ilmu Pendidikan Teoritis Dan Praktis (Bandung: PT Remaja Rosdakarya, 1998).

${ }^{2}$ Maspalah, 'Penggunaan Permainan Memasangkan Kartu Dalam Pembelajaran Bahasa Arab DI SMA’ Bahasa \& Sastra', Jurnal, 13.1 (2013), 2.

${ }^{3}$ Nanang Joko Purwanto, 'Lagu Sebagai Media Pembelajaran Tata Bahasa Arab (Nahwu)', Jurnal Mabarat, 1.1 (2018), 2.

${ }^{4}$ Hasan Baharun, 'Penerapan Pembelajaran Active Learning Untuk Meningkatkan Hasil Belajar Siswi Madrasah', Jurnal Pendidikan Pedagogik, 1.1 (2015), 35.

${ }^{5}$ Depdiknas, Lampiran Permendiknas Nomor 22 Tentang Standar Isi (Jakarta: Balitbang Puskur, 2006).

${ }^{6}$ Ach. Sholehuddin, 'Implementasi Metode Amtsilati Dalam Meningkatkan Kemampuan Maharah Qira'ah' Jurnal', Jurnal Arabiyatuna, 3.1 (2019), 48.
} 
pendidikan sangat begitu cepat, juga bahasa arab merupakan bahasa kitab suci dan tuntutan agama Umat Islam sedunia ${ }^{7}$.

Hingga bahasa Arab mempunyai kedudukan yang sama dengan bahasabahasa yang lain di tingkat dunia. Sebagaimana disampaikan Azhar Arsyad dalam Buku penelitiannya yakni, 'Bahasa Arab termasuk salah satu bahasa resmi yang di pergunakan untuk Perserikatan Bangsa-Bangsa (PBB) kurang lebih 20 Negara, dan juga bahasa Arab menjadi bahasa mayor di dunia yang diturunkan lebih dari 200.000.000 umat manusia’8.

Maka dari itu, untuk mencetak para generasi yang sangat unggul di bidangnya, dalam belajar bahasa Arab diperlukan guru yang kreatif, berani, telaten, serta mampu mengasah para siswinya dalam meningkatkan motivasi berbicara bahasa Arab sesuai dengan kaidah dan struktur kosa kata (mufrodat) yang baik. Dalam hal ini, kehadiran sekolah Madrasah Aliyah Nurul Jadid (MANJ) Paiton Probolinggo sangatlah berfungsi guna menjadi ladang pembelajaran bagi peserta didik dalam menuntut ilmu. Yang mana merupakan sebuah sekolah yang mengedepankan kualitas Sumber Daya Manusia (SDM). Dalam hal ini guru bahasa Arab merupakan dari SDM yang ada?

Madrasah ini telah mewadahi para tenaga pendidik yang trampil, disiplin dan bertanggung jawab serta siap mengajar para siswinya, dengan penuh kreatif. Sebagaimana yang telah di kutip pembicaraan dari salah satu guru bahasa Arab di madrasah tersebut " العلم بالتعلم واللغة بالتكلم" ilmu itu dengan belajar dan bahasa itu dengan berbicara, Jadi untuk menjadi guru Bahasa Arab yang mampu membuat para siswinya paham maka dengan cara mempraktekkan dengan media dan metode yang mudah di pahami ${ }^{10}$.

Salah satu pendekatan yang tepat untuk meningkatkan kemampuan menghafal siswi Madrasah Aliyah Nurul Jadid yaitu dengan mengimplementasikan mnemonik. Metode ini merupakan teknik yang telah digunakan oleh guru Madrasah Aliyah Nurul Jadid ketika mengajar pembelajaran bahasa Arab terhadap para siswinya

7 Batmang, 'Direct Method Dalam Pembelajaran Bahas Arab Di Pesantren Modern', Jurnal Al-Ta'dib, 2.6 (2013), 171.

8 Azhar Arsyad, Bahasa Arab Dan Metode Pengajarannya (Yogyakarta: Pustaka Belajar, 2004).

${ }^{9}$ Ahmad Muzakki, Wawancara Tanggal 24 Desember (Probolinggo, 2019).

10 Afridatul Laily, Wawancara Tanggal 27 Desember (Probolinggo, 2019). 
dikelas. Mnemonik ini merupakan solusi kreatif yang merupakan alat pengait dalam memacu meningkatkan kemampuan mengingat (merecell) informasi yang terdapat dalam memori seseorang ${ }^{11 .}$ Seperti definisi singkat yang telah di paparkan oleh Bellezza mengungkapkan metode mnemonik merupakan metode mentlansfer materi kedalam memori jangka panjang yang mudah di terima oleh otak manusia ${ }^{12}$.

Dalam menghafal tentunya tidak cukup seseorang hanya mengingat dengan proses menggunakan otak kiri karena hanya berfungsi menganalitis/akademis diantara bagian-bagiannya mengaitkan logika, kata-kata, angka, matematis, berpikir urutan, rutinitas/pengulangan detail dan terorganisasi yang berada di belahan fungsi otak kiri. Sedangkan perbandingan dengan otak kanan yaitu melalui dengan banyak ragam yang terdiri dengan sesuatu kreatif diantanya: Irama, musik, gambar, imajinasi, konseptual, berpikir acak, intuisi dan global/menyeluruh ${ }^{13 .}$ Tentunya jika mengingat sesuatu hanya mengandalkan informasi otak kiri saja dalam menghafal maka akan lebih mudah hilang karena dapat memberikan kebosanan tersendiri bagi setiap diri seseorang.

Pembelajaran dengan sistem mnemonik memberikan makna kepada para siswi Madrasah Aliyah Nurul Jadid untuk lebih mudah dalam membantu mengingat hafalan, dan bertahan dengan jangka waktu yang lebih lama. Dalam penerapannya melalui mnemonik yang berupa metode Asosiasi teknik cerita dan rima, bahwa dalam mengingat atau menghafal sesuatu, secara tidak langsung mampu menggabungkan antara otak kiri dan otak kanannya dengan bekerja sama saat belajar ${ }^{14}$.

Sebelum membahas tentang pengertian mnemonik, peneliti memaparkan sedikit tentang kekuatan menghafal dari memori otak manusia dengan jangka waktu yang tertentu. Belajar dengan menghafal merupakan hal yang sulit dan membosankan di kalangan para siswi. Di karenakan membuat mata pelajaran tidak dapat diingat dengan baik sehingga berpengaruh terhadap hasil belajar siswi.

\footnotetext{
${ }^{11}$ Hasan Baharun, 'Penguatan Daya Ingat Mahasantri Melalui Mnemonic Learning', Jurnal Pedagogik, 5.2 (2018), 182.

${ }^{12}$ Risna Rianti Sari, 'Mnemonik Sebagai Alternatif Dalam Menghafal Kosakata Bahasa Arab', Jurnal Tarbiyatuna, 3.2 (2018), 39.

13 E.K Wijaya, 'Pemanfaatan Modul Mnemonik (Modul Ingatan) Dalam Pembelajaran Program Paket C Untuk Meningkatkan Hasil Belajar', Jurnal Pendidikan Luar Sekolah, 5.1 (2012), 11.

14 Ahmad Zainudin and Khozinul Asror, 'Metode Mnemonic: Solusi Kreatif Untuk Meningkatkan Pemahaman Nahwu Bagi Mahasiswa', in Sminar Nasional, 2019, p. 1.
} 
Tulving dan Craick mengungkapkan dalam Sternberg ${ }^{15}$ bahwa seluruh informasi hasil belajar seseorang akan tersimpan di dalam memori untuk di gunakan pada waktu selanjutnya. Memori memiliki beberapa area penyimpanan yang dapat menyimpan informasi dengan durasi lama dan kapasitas penyimpanan yang banyak ialah memori jangka panjang.

Memori jangka panjang di definisikan oleh Atkinson dan Shiffin sebagai suatu proses penyimpanan yang relatif permanen. Hal tersebut di perjelas oleh Hudman menyatakan bahwa penyimpanan memori jangka panjang sangat luas dalam artian bisa bermenit-menit, berjam-jam, hingga sepanjang hidup manusia. Oleh karenanya memori jangka panjang merupakan penyimpana informasi hasil belajar maupun pengalaman yang dipertahankan dalam waktu yang lama saat di gunakan kembali jika di butuhkan ${ }^{16}$.

\section{KAJIAN PUSTAKA}

\section{MNEMONIK}

Pada mulanya mnemonik merupakan sebuah induk berbagai pemikiran ${ }^{17}$. Dengan adanya mnemonik dapat memudahkan dan merangsang seseorang dalam meningkatkan daya ingat, Yang mana menurut Amiryousefi Muhammad dan Saeed Ketabi didalam jurnalnya, Mnemonik diambil dari sebuah nama seorang dewa Mnemosyne yang berarti dewa ingatan ${ }^{18 .}$ Yang juga di dalam mithodologi Yunani, mnemonic diartikan sebagai alat bantu mengingat seperti yang telah di paparkan oleh Baharun yakni penuh perhatian ${ }^{19}$. Mnemonik pada masa kepemimpinan itu, hanya digunakan saat penghafalan orasi saja dalam mengingat pidato untuk lebih terkesan dengan kemampuan berdebat dalam pemerintahannya. Dengan bergulirnya waktu metode mnemonik, terkenal dengan trik yang ampuh dalam meningkatkan kemampuan mengingat secara umum.

\footnotetext{
${ }^{15}$ Sternberg, Psikologi Kognitif (Yogyakarta: Pustaka Belajar, 2008).

${ }^{16}$ Aminah Rehalat, 'Model Pembelajaran Pemrosesan Informasi', Jurnal Pendidikan Ilmu Sosial, 2 (2014), 9 .

17 Elda Adriana, 'Efektifitas Metode Mnemonik Kata Kunci Dalam Peningkatan Kemampuan Siswa Terhadap Penguasaan Kosakata Bahasa Arab’, 2017.

$18 \mathrm{M}$. Amiryousefi and S. Ketabi, 'Mnemonic Instruction: A Way to Boost Vocabulary Learning and Recall', Journal of Language Teaching and Research, 2.1 (2011), 178.

${ }^{19}$ Baharun, 'Penguatan Daya Ingat Mahasantri Melalui Mnemonic Learning'.
} 
Mnemonik merupakan sebuah teknik yang bisa di gunakan oleh seorang guru dalam meningkatkan kemampuan menghafal kosa kata bahasa asing dengan cara mengasosiasikan pikiran yang dapat memahami suatu kata-kata, ide, gambaran, khayalan dalam meningkatkan kapasitas ingatan seseorang dengan mengingat sesuatu yang baru dengan cara yang mudah dan gampang ${ }^{20}$. Laing juga menyatakan di dalam penelitiannya bahwa dalam menggunakan teknik mnemonik dapat meningkatkan kemampuan mengingat serta menjawab pertanyaan yang lebih bervariasi ${ }^{21 .}$ Menurut Bakken \& Simpson menyatakan teknik mnemonik merupakan cara yang afektif guna dapat di terapkan oleh semua siswi dalam menyusun kalimat yang sulit ${ }^{22}$. Hal ini sependapat dengan penelitian Sardjana menyebutkan bahwasanya metode mnemonik sebagai 'jembatan keledai' karena berfikiran bahwa metode ini memang merupakan metode yang dapat membantu ingatan seseorang dengan mudah ${ }^{23}$. Dan juga teknik mnemonik merupakan metode yang mampu membantu siswi dalam belajar meningkatkan daya ingat menghafal dengan cara berimajinasi dan berasosiasi. Dimana, menurut Choirun Nisak menyatakan imajinasi merupakan daya pikir untuk bersungguh-sungguh menghayati dengan berimajinatif materi yang disampaikan dan bagaiman ia mengasosiasikannya ${ }^{24}$.

\section{TEKNIK-TEKNIK MNEMONIK}

Teknik-teknik Mnemonik terdiri dari beberapa jenis, yang semuanya berfungsi dalam mempermudah belajar dan memperkuat ingatan seseorang dalam menghafal kosa kata bahasa Asing. Menurut perspektif Syah, ${ }^{25}$ teknik-teknik ini mempunyai banyak ragamnya, namun yang lebih dominan diantaranya: Rima (Rhyme), singkatan (Akrostik), sistem kata pasak (peg word system), metode losai (Method of loci), sistem kata

${ }^{20}$ Sari.

${ }^{21}$ Laing, 'An Empirical Test of Mnemonic Devices to Improve Learning in Elementarary Accounting', Journal of Education For Business, 5.6 (2010), 350.

${ }^{22}$ P Bakken, J and C.G Simpson, 'Mnemonik Strategies: Success For The Young-Adult Learner', The Journal of Human Resource and Adult Learning, 7.2 (2011), 1.

${ }^{23}$ Yokhanan Ardika and A. Sardjana, 'Efektivitas Metode Mnemonik Ditinjau Dari Daya Ingat Dan Hasil Belajar Matematika Siswa SMK Kelas X', Jurnal KREANO, 7.1 (2016), 67.

${ }^{24}$ Umi Choirun Nisak and Dkk, Validity Of Vidio Media Integrated With Mnenemonik Rhymes And Songs On Human Motion System Matter And Matter And Its Effect On Students Retention Of Grade XI Of SENIOR High School', Jurnal Bioedu Berkala Ilmah Pendidikan Biologi, 6.1 (2017), 71.

${ }^{25}$ Muhibbin Syah, Pesikologi Belajar (Jakarta: PT Raja Grafindo Persada, 2012). 
kunci (key word system)dan pengelompokan. Sedangkan menurut Fitria Lestari dkk di dalam jurnalnya, ${ }^{26}$ mempunyai kesamaan dengan teori diatas yang telah di ketahui, namun lebih sedikit dalam penguraiannya. yaitu Akronim, Akrostik, teknik losai dan pancang. Berikut smua pengertian dan contoh-contohnya yang terurai di bawah ini:

1. Rima (Rhyme), yaitu merupakan sajak di buat sedemikian rupa yang terdiri dari ritem, melodi, dan pengulangan. Biasanya dengan memutarkan rima tersebut akan tercipta sebuah penggambaran pada memori audio seseorang yang tlah mendengarkan dengan mengingat kembali kata-kata yang telah tersimpan dan juga sangat berguna bagi ingatan jangka panjang.

2. Akronim merupakan singkatan $\mathrm{kata}^{27}$ yang mana ketika memakai huruf pertama dari suatu kalimat hingga menjadi suatu kata baru. Misalnya kata ABRI merupakan singkatan dari Angkatan Bersenjata Republik Indonesia. Contoh lain menghafal dalam mempermudah mengingat nama Nabi Adam, Nabi Nuh, Nabi Ibrohim, Nabi Musa dapat disingkat menjadi ANIM.

3. Akrostik yaitu metode kalimat, juga menggunakan huruf kunci awal dalam membuat konsep abstrak yang diringkas lebih pendek dengan sedemikian gaya yang harus di ingat siswi. Seperti contoh: ketika siswi dalam belajar ilmu tajwid yang hendak mempermudah mengingat huruf-huruf Qolqolah ada lima ب ج د طق. bisa disingkat dengan BAJU DI TOKO(Markowitz 2002).

4. Sistem kata pasak (peg word system) yaitu sejenis yang menggunakan unsur-unsur sebelumnya telah dikuasai sebagai pasak ( $p a k u$ ) pengait memory baru. kata unsur pasak yang dibentuk berpasang-pasangan seperti merah-saga, jernih-air. Kata-kata tersebut berguna dalam mengingat istilah yang memiliki watak yang sama seperti darah, lipstik: pasangan surga, neraka dan kata lain yang telah memiliki kesamaan watak (warna, rasa dan seterusnya).

5. Metode losai (Method of loci) merupakan alat Mnemonik biasanya teknik ini berfungsi mengasosiasikan tempat-tempat atau benda-benda khusus untuk menghafal sarana dan penempatan kata istilah tertentu yang biasanya melibatkan

${ }_{26}$ Fitria Lestari and Dkk, 'Pengaruh Teknik Mnemonik Terhadap Hasil Belajar Materi Spermatophyta Siswa Kelas X SMAN 3 Lubuklinggau', Jurnal Perspektif Pendidikan, 8.2 (2014), 137.

${ }^{27}$ Pius A Partanto, Kamus Ilmiah Populer (Surabaya: Arkola, 2001). 
tempat sebagai ingatan visual/asosiasi, yang harus diingat oleh siswi. ${ }^{28}$ Penggunaan metode ini mengharuskan seseorang memiliki kekuatan imajinasi yang kuat dalam menggambarkan segala sesuatu yang ingin di ingatnya. Contoh: misalnya kita akan pergi ke pasar untuk berbelanja, dan kita ingin menghafal daftar belanjaan tersebut, yakni: susu, daging, pisang dan sosis. Kemudian kita membayangkan benda-benda tersebut pada tempat yang tepat. Semisal, membayangkan perjalanan dari kandang sapi ke kamar. Kita membayangkan ada seember susu di sebelah tempat kandang sapi, ketika melewati dapur kita melihat daging-daging sapi bergelantungan dimana-mana, melihat pisang super besar sebagai gagang pintu, dan sosis berukuran jumbo berguling-guling diatas kasur tempat tidur. Kemudian setelah sampai di pasar, secara mental kita membayangkan rute yang tadi di bayangkan, sembari me-recall item-item apa saja yang tadi dibayangkan.

6. Pemotongan/ pengelompokan, yakni teknik ini umumnya sering di pakai dalam mengingat, menghafal bilangan atau angka, contoh untuk angka semisal nomor 085215563715 , bisa kita potong dalam bentuk 085215563715 .

Hal inilah yang menjadikan daya tarik peneliti untuk terus meneliti lebih dalam tentang: Bagaimana usaha guru menerapkan mnemonik dalam mengajar kosa kata bahasa Arab di Madrasah Aliyah Nurul Jadid? dan teknik apa saja yang dibutuhkan dalam mempermudah mengingat hafalan bagi para siswi tersebut?

\section{METODE PENELITIAN}

Tujuan penelitian ini yaitu untuk mengetahui bagaimana usaha guru menerapkan mnemonik sebagai solusi kreatif dalam mengajar kosa kata bahasa Arab siswi di Madrasah Aliyah Nurul Jadid Paiton Probolinggo. Juga untuk mengetahui teknik-teknik apa saja yang di butuhkan dalam mempermudah mengingat kemampuan menghafal bagi para siswi Madrasah Aliyah Nurul Jadid. penelitian ini menggunakan pendekatan deskriptif jenis kualitatif ${ }^{29}$.

Pada tahap ini peneliti memposisiskan sebagai human instrument, pengumpulan data yang dilakukan melalui wawancara dengan guru dan siswi untuk

\footnotetext{
${ }^{28}$ Karen Markowitz and Eric Jensen, Otak Sejuta Gigabyte (Bandung: Kaifa, 2002).

${ }^{29}$ Lexy J.Moleong, Metodologi Penelitian Kualitatif (Bandung: Remaja Rosdakarya, 2002).
} 
mendapatkan informasi secara langsung dan mengamati fenomena yang terjadi tentang hal-hal yang berkaitan dengan metode pembelajaran melalui mnemonik dan teknik-teknik apa saja yang telah di lakukan oleh guru dalam meningkatkan kemampuan menghafal kosa kata pembelajaran bahasa Arab dengan mudah saat mengajar di kelas. Subjek dalam penelitian ini adalah siswi dan guru yang mengajar bahasa Arab. sedangkan objeknya adalah Madrasah Aliyah Nurul Jadid Paiton Probolinggo.

\section{MNEMONIK SEBAGAI METODE KREATIF DALAM PEMBELAJARAN BAHASA ARAB DI MADRASAH ALIYAH NURUL JADID}

Sebagai tenaga pendidik (guru), berkreativitas dalam pembelajaran memiliki peran yang cukup penting bagi peserta didik untuk membantu mereka dalam memahami materi pelajaran yang telah di ajarkan. Untuk itu peserta didik yang telah mengikuti materi pelajaran tersebut tidak akan merasa bosan dan malas untuk belajar. mereka akan selalu merasa senang apabila pelajaran yang mereka pelajari merasa tidak menyulitkan dan menyusahkan. Lalu akan timbul minat yang besar untuk selalu belajar dan mempelajari materi pelajaran tersebut lebih khususnya pelajaran bahasa Arab. Dalam mengajar pembelajaran bahasa Arab tentunya seorang guru telah mempersiapkan bahan apa saja yang cocok untuk diajarkan kepada para siswinya dalam mengajar kosa kata bahasa Arab dengan mudah di Madrasah Aliyah Nurul Jadid dalam menilai sejauh mana para siswinya memahami dan meningkatnya kemampuan menghafal kosa kata pelajaran bahasa tersebut. untuk itu, ada banyak cara guru Madrasah Aliyah Nurul Jadid dalam menerapkan bahan ajar yang mudah dan menarik untuk di pahami oleh para siswinya di antaranya adalah:

1. Guru mempunyai power atau publik speaking yang baik, lucu, semangat penuh bergairah saat mengajar dan trampil hingga peserta didik yang berada di dalam kelas tidak pernah merasa jenuh saat mendapati Kegiatan Belajar Mengajar (KBM) bahasa arab berlangsung.

2. Menyukai tantangan. Guru dapat melihat potensi masing-masing dan ke unikan anak-anak. dengan hal ini guru bisa lebih mudah mengetahui dari kereativitaskreativitas mesing-masing anak tersebut. 
3. Sebagai motivator. Sebagai seorang guru sering kali memberikan dorongan dan semangat agar siswi selalu belajar dengan giat nan semangat.

4. Selalu meng evaluasi. Dengan ini guru harus sering menilai, yakni kemampuan intelektual, sikap dan tingkah laku yang mereka kerjakan, agar guru dapat mengetahui perkembangan sejauh mana mereka ber kreatif dan berlombalomba dalam mendapat nilai terbaik. ${ }^{30}$ Dengan pembelajaran yang mereka pelajari hal ini memicu semangat dan juga mendapat hasil yang lebih optimal.

Dan cara yang kedua dalam mengajar bahasa Arab guru Madrasah Aliyah Nurul Jadid Telah menerapkan dan Memperbanyak menggunakan metode yang tidak hanya terpaku pada buku teks, (LKS) di antara yang telah di lakukan guru saat mengajar di Madrasah Aliyah Nurul Jadid ialah dengan menggunakan teknik-teknik mnemonik. Berdasarkan prosesnya, guru memancing semangat para siswi dengan memberikan nilai secara terang-terangan bagi para siswi yang aktif dalam menjawab pertanyaan yang berkaitan dengan mata pelajaran bahasa Arab, kemudian guru memulai dengan mengulang materi yang telah disampaikan dari minggu sebelumnya dan juga mengacak mufrodat yang telah di hafalkan oleh siswi, setelah itu guru memberikan tugas kepada para siswi agar mufrodat yang telah diberikan dirangkai menjadi sebuah kalimat berupa cerita, rima atau lagu yang bisa meningkatkan daya ingat siswi dalam menghafal mufrodat. Pendapat tersebut dapat dilakukan dengan cara berlatih dengan sungguh-sungguh sehingga hasilnya bisa sesuai dngan tujuan yang diharapkan. ${ }^{31}$

Dengan adanya mnemonik ini akan menjadi solusi kreatif yang tepat, guna membantu para siswi agar selalu tetap bersemangat untuk terus mengikuti kegiatan belajar mengajar khususnya saat menghafal kosa kata pembelajaran bahasa Arab yang sulit. Dari hasil pernyataan diatas menunjukkan bahwa; pembelajaran bahasa Arab yang dengan pendekatan Mnemonik di Madrasah Aliyah Nurul Jadid Paiton Probolinggo afektif di lakukan melalui:

30 Syaikhudin Ahmad, 'Pengembangan Kreativitas Guru Dalam Proses Pembelajaran', LISAN, 5.2 (2013), 306.

${ }^{31}$ Hasan Baharun, 'Pengembangan Media Pembelajaran PAI Berbasis Lingkungan Melalui Model ASSURE', Cendekia: Journal of Education and Society, 14.2 (2016), 235. 


\section{Metode Asosiasi teknik cerita}

Metode ini merupakan cara dan usaha guru Madrasah Aliyah Nurul Jadid Paiton Probolinggo dalam membantu mempermudah dan menarik perhatian para siswinya dalam mengingat kosa kata bahasa asing dengan cara menghubungkan antara satu informasi yang diingat dengan informasi yang baru di ingat ${ }^{32}$ Semisal kata Misymisun (مِشْمِشَ) yang artinya Manggis, dapat di asosiasikan menjadi 'Mis...Amis buah Manggis' atau semisal lagi Bahara (بَ) yang artinya Perahu, dapat di asosiasikan menjadi 'Bahar membakar Perahu' ${ }^{33}$.

Asosiasi $^{34}$ tidak hanya digunakan dalam menghafal kosa kata satu per satu, namun juga dapat digunakan dengan satu tema yang saling berhubungan untuk memudahkan para siswi dalam menghafal kosa kata secara acak. Kemudian membuat teknik cerita yang saling mengaitkan agar mudah diingat. Setelah diurutkan terdapat kelompok kosa kata yang biasa diambil dalam contoh buku LKS para siswi, haziro, miroron, dan sakata. Yang jika diurut artinya sedih, sering dan diam. Maka dapat di hubungkan menjadi bentuk cerita Ikhsan bersedih karena melihat roro yang sering diam karena sakit.

Semakin lucu kosa kata yang dibuat oleh guru dan siswi dengan cara dihubungkan dengan berbentuk cerita maka semakin berimajinasi pula para siswi tersebut untuk lebih mudah mengingat yang di hafal dengan waktu yang lebih panjang.

Asosiasi berupa teknik cerita merupakan metode yang afektif. Dengan mengimplementasikan metode tersebut telah berhasil membuat para peserta didik semangat dalam mengikuti kegiatan belajar mengajar lebih khususnya dalam pembelajaran bahasa Arab. Dengan hal ini tugas guru sebagai pendidik harus lebih telaten dan mampu memilih metode dan model pembelajaran yang tepat agar dapat menciptakan proses pembelajaran yang mudah dan menyenangkan saat di kelas.

\footnotetext{
32 Yovan P. Putra, Lejitkan Memori 1000 \% (Jakarta: Elex Media Computindo, 2010).

${ }^{33}$ Ida Hanif Mahmud and Hanifuddin Mahadun, Abaa Aku Bisa, Contob Teknik Menghafal Cepat Pelajaran (Jombang: Yayasan I'anatul Mubtai'in, 2007).

34 Tim Penyusun Kamus Pusat Pembinaan dan Pengembangan Bahasa Departemen Pendidikan dan Kebudayaan, Kamus Besar Bahasa Indonesia (Jakarta: Balai Pustaka, 2005).
} 
Dari hasil penelitian dilapangan jika di bandingkan dengan teori yang di ambil dari peneliti tidak jauh berbeda. Bahwasannnya dalam konteks tersebut, sebagian mnemonik terdapat kesamaan dengan teori asosiasi, yaitu berfungsinya 'cerebral cortex' dalam penerapan informasi, karena ingatan tersebut 'diikat", dan telah di-recall (dimunculkan) kembali dalam bentuk ingatan ${ }^{35}$.

\section{Rhyme}

Rima merupakan teknik yang juga di terapkan guru Madrasah Aliyah Nurul Jadid saat mengajar para siswinya. Melalui media ini hambatan belajar akan hilang dan juga mudah membangkitkan semangat siswi untuk lebih giat dalam belajar, hingga pada akhirnya dapat mencapai hasil yang memuaskan dan dapat memotivasi belajar siswi ${ }^{36}$. Dalam mendesain pembelajaran bahasa Arab, siswi di ajak untuk menulis mufradat yang sulit di ingat menurut mereka yang ada di buku LKS, lalu guru memberikan contoh instrumen lagu-lagu yang cocok untuk di hafalkan dengan mencantumkan kosa kata mufradat yang akan hendak mereka hafalkan, di antara lagu-lagu yang sering di gunakan yaitu melodi lagu Irwanshah yang berjudul 'pencinta wanita' yang di ubah judulnya في العدرسة (di sekolah) dan aransement lagu hindia yang berjudul 'kuch-ho ta hai' seperti contoh bentuk lagu di bawah ini:

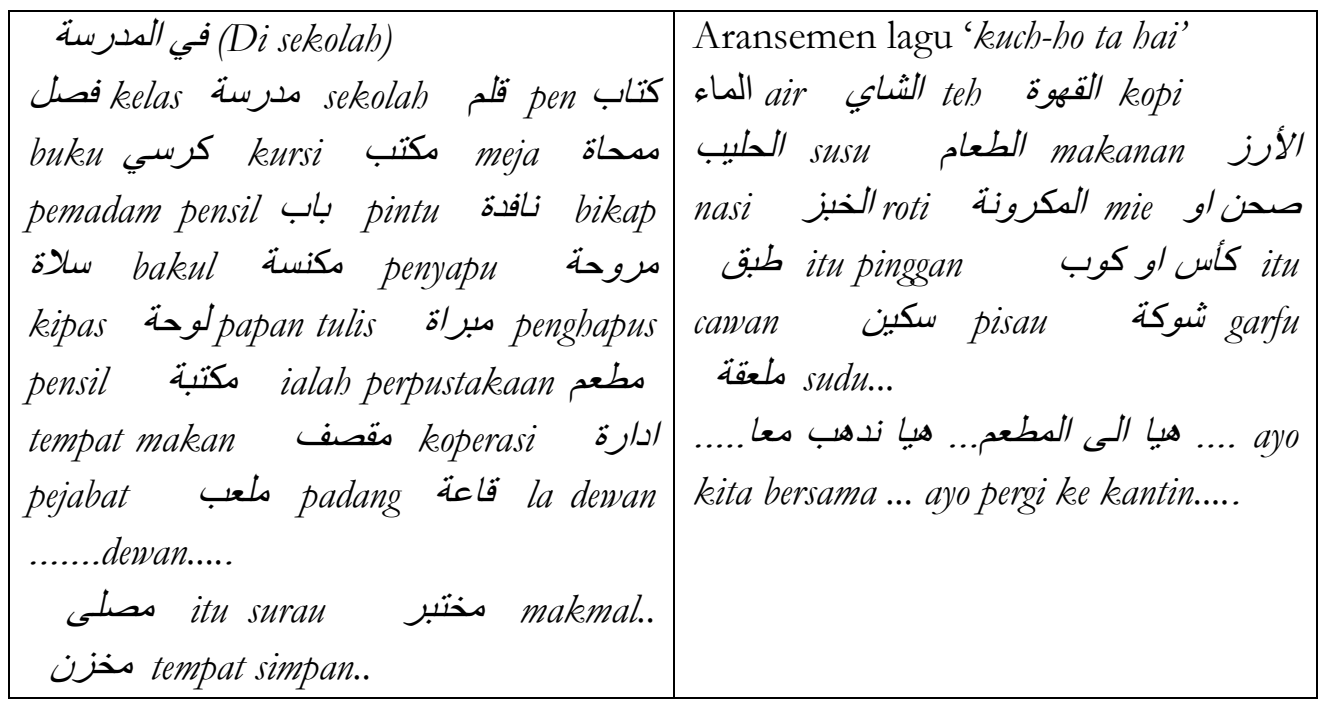

${ }^{35}$ Suwito NS, 'The Art of Memory Dan Estetika Pembelajaran (Implementasi Mnemonic Dalam Pembelajaran Bahasa Arab', Jurnal Ibda' Studi Islam Dan Budaya, 3.2 (2005), 6.

${ }_{36}$ Moh Imron and Dkk, 'Keefektifan Strategi Asosiasi Kotak Kata Dalam Meningkatkan Motivasi Belajar Dan Kemampuan Peserta Didik Dalam Menghafal Asmaul Husna', Jurnal Pedagogik, 5.1 (2018), 146. 
Banyak lagi lagu yang bisa dijadikan contoh dalam menghafal kosa kata bahasa Arab lainnya. Dengan cara seperti itu, membuat para siswi terpancing untuk lebih kreatif dalam mencari mufradat yang sulit untuk di ingat dan ditulis sesuai dengan nada musik slide (power point) yang telah di sediakan guru saat pembelajaran berlangsung. Hal tersebut sangatlah berpengaruh terhadap semangat siswi untuk selalu tertarik dan berantusias saat menghafal kosa kata bahasa Arab di Madrasah Aliyah Nurul Jadid Paiton Probolinggo.

Belajar bahasa Arab memang tidak gampang bagi mereka yang kurang terbiasa memperaktekkan berbicara dengan menggunakan bahasa Arab sehari-hari hingga terasa sulit dan membuat mereka kurang senang mempelajarinya apalagi menghafalnya. Namun dengan metode yang telah di ajarkan oleh para guru bahasa Arab setiap harinya bervariasi, salah satunya dengan teknik rbyme tersebut akan membuat mereka para siswi selalu tertarik dan tidak bosan saat menghafal dan mengikuti mata pelajaran bahasa Arab dengan tertib.

Hasil dari penelitian diatas sesuai dengan teori yang telah di paparkan oleh Lezanov dalam penelitiannya menyimpulkan ketika menghafal dalam mengingat (Ricell) dengan menggunakan musik lebih mempercepat kemampuan daya ingat rata-rata $97 \%{ }^{37}$. Selanjutnya, teori diatas di perkuat dengan teori yang telah di paparkan oleh Choirun Nisak dalam jurnalnya menyatakan bahwasanya menggunakan media vidio terintegrasi mnemonic rhymes and songs dengan ditambah pengajaran menggunakan media slide power point, sangat berpengaruh terhadap daya ingat menghafal siswi ${ }^{38}$.

Dengan teknik dan metode yang telah di contohkan di atas merupakan trik yang ampuh dan mempermudah dalam melatih ingatan para siswi saat menghafal kosa kata bahasa Arab, juga mempermudah bagi para guru saat mengajar bahasa arab dalam menarik perhatian mereka.

\footnotetext{
${ }^{37}$ Don Campbell, Efek Mozart (Jakarta: Gramedia, 2001).
}

${ }^{38}$ Nisak and Dkk. 


\section{KESIMPULAN}

Berdasarkan hasil penelitian yang telah dilaksanakan di Madrasah Aliyah Nurul Jadid maka peneliti bisa menarik kesimpulan bahwa usaha guru dalam mengajar harus memiliki pertama power atau publik speaking yang baik, agar peserta didik yang berada di dalam kelas tidak pernah merasa jenuh saat mendapati Kegiatan Belajar Mengajar (KBM) bahasa arab berlangsung. Kedua Menyukai tantangan, Guru dapat melihat potensi masing-masing dan ke unikan para siswi, dengan hal ini guru bisa lebih mudah mengetahui dari kereativitas-kreativitas mesing-masing siswi tersebut. Ke tiga Sebagai motivator. Sebagai seorang guru sering kali memberikan dorongan dan semangat agar siswi selalu belajar dengan giat nan semangat. Ke empat Selalu meng evaluasi. Dengan ini guru harus sering menilai, yakni kemampuan intelektual, sikap dan tingkah laku yang mereka kerjakan, agar guru dapat mengetahui perkembangan sejauh mana mereka ber kreatif dan berlomba-lomba dalam mendapat nilai terbaik. Terakhir dalam mengajar bahasa Arab guru Madrasah Aliyah Nurul Jadid Telah menerapkan dan Memperbanyak menggunakan metode yang tidak banya terpaku pada buku teks, (LKS) di antara yang telah di lakukan guru Madrasah Aliyah Nurul Jadid ialah dengan menggunakan teknik-teknik mnemonik.

1. Pembelajaran bahasa Arab menggunakan mnemonik dengan asosiasi teknik cerita sangat membantu mempermudah dan menarik perhatian para siswinya dalam mengingat kosa kata bahasa asing dengan cara menghubungkan antara satu informasi yang diingat dengan informasi yang baru di ingat.

2. Pembelajaran bahasa Arab menggunakan mnemonik berupa teknik rhyme. teknik ini sangat membantu siswi untuk menghafal kosa kata dalam bahasa Arab. dapat dilihat dari hafalan nyanyiannya, yang mana lirik lagunya sudah diganti dengan kosa kata bahasa Arab.

\section{DAFTAR PUSTAKA}

Adriana, Elda, 'Efektifitas Metode Mnemonik Kata Kunci Dalam Peningkatan Kemampuan Siswa Terhadap Penguasaan Kosakata Bahasa Arab’, 2017

Ahmad, Syaikhudin, 'Pengembangan Kreativitas Guru Dalam Proses Pembelajaran', LISAN, 5 (2013), 306

Amiryousefi, M., and S. Ketabi, 'Mnemonic Instruction: A Way to Boost Vocabulary Learning and Recall', Journal of Language Teaching and Research, 2 (2011), 178 
Ardika, Yokhanan, and A. Sardjana, 'Efektivitas Metode Mnemonik Ditinjau Dari Daya Ingat Dan Hasil Belajar Matematika Siswa SMK Kelas X', Jurnal KREANO, 7 (2016), 67

Arsyad, Azhar, Bahasa Arab Dan Metode Pengajarannya (Yogyakarta: Pustaka Belajar, 2004)

Baharun, Hasan, 'Penerapan Pembelajaran Active Learning Untuk Meningkatkan Hasil Belajar Siswi Madrasah', Jurnal Pendidikan Pedagogik, 1 (2015), 35

_- 'Pengembangan Media Pembelajaran PAI Berbasis Lingkungan Melalui Model ASSURE', Cendekia: Journal of Education and Society, 14 (2016), 235

_- 'Penguatan Daya Ingat Mahasantri Melalui Mnemonic Learning', Jurnal Pedagogik, 5 (2018), 182

Bakken, J, P, and C.G Simpson, 'Mnemonik Strategies: Success For The YoungAdult Learner', The Journal of Human Resource and Adult Learning, 7 (2011), 1

Batmang, 'Direct Method Dalam Pembelajaran Bahas Arab Di Pesantren Modern', Jurnal Al-Ta'dib, 2 (2013), 171

Campbell, Don, Efek Mozart (Jakarta: Gramedia, 2001)

Depdiknas, Lampiran Permendiknas Nomor 22 Tentang Standar Isi (Jakarta: Balitbang Puskur, 2006)

Imron, Moh, and Dkk, 'Keefektifan Strategi Asosiasi Kotak Kata Dalam Meningkatkan Motivasi Belajar Dan Kemampuan Peserta Didik Dalam Menghafal Asmaul Husna', Jurnal Pedagogik, 5 (2018), 146

J.Moleong, Lexy, Metodologi Penelitian Kualitatif(Bandung: Remaja Rosdakarya, 2002)

Kebudayaan, Tim Penyusun Kamus Pusat Pembinaan dan Pengembangan Bahasa Departemen Pendidikan dan, Kamus Besar Bahasa Indonesia (Jakarta: Balai Pustaka, 2005)

Laily, Afridatul, Wawancara Tanggal 27 Desember (Probolinggo, 2019)

Laing, 'An Empirical Test of Mnemonic Devices to Improve Learning in Elementarary Accounting', Journal of Education For Business, 5 (2010), 350

Lestari, Fitria, and Dkk, 'Pengaruh Teknik Mnemonik Terhadap Hasil Belajar Materi Spermatophyta Siswa Kelas X SMAN 3 Lubuklinggau', Jurnal Perspektif Pendidikan, 8 (2014), 137

Mahmud, Ida Hanif, and Hanifuddin Mahadun, Ahaa Aku Bisa, Contob Teknike Menghafal Cepat Pelajaran (Jombang: Yayasan I'anatul Mubtai'in, 2007)

Markowitz, Karen, and Eric Jensen, Otak Sejuta Gigabyte (Bandung: Kaifa, 2002)

Maspalah, 'Penggunaan Permainan Memasangkan Kartu Dalam Pembelajaran Bahasa Arab DI SMA' Bahasa \& Sastra', Jurnal, 13 (2013), 2

Muzakki, Ahmad, Wawancara Tanggal 24 Desember (Probolinggo, 2019)

Nisak, Umi Choirun, and Dkk, Validity Of Vidio Media Integrated With Mnenemonik Rhymes And Songs On Human Motion System Matter And Matter And Its Effect On Students Retention Of Grade XI Of SENIOR High School', Jurnal Bioedu Berkala Ilmah Pendidikan Biologi, 6 (2017), 71

NS, Suwito, 'The Art of Memory Dan Estetika Pembelajaran (Implementasi Mnemonic Dalam Pembelajaran Bahasa Arab', Jurnal Ibda' Studi Islam Dan Budaya, 3 (2005), 6

Partanto, Pius A, Kamus Ilmiah Populer (Surabaya: Arkola, 2001)

Purwanto, M. Ngalim, Ilmu Pendidikan Teoritis Dan Praktis (Bandung: PT Remaja Rosdakarya, 1998) 
Purwanto, Nanang Joko, 'Lagu Sebagai Media Pembelajaran Tata Bahasa Arab (Nahwu)', Jurnal Maharat, 1 (2018), 2

Putra, Yovan P., Lejitkan Memori 1000 \% (Jakarta: Elex Media Computindo, 2010)

Rehalat, Aminah, 'Model Pembelajaran Pemrosesan Informasi', Jurnal Pendidikan Ilmu Sosial, 2 (2014), 9

Sari, Risna Rianti, 'Mnemonik Sebagai Alternatif Dalam Menghafal Kosakata Bahasa Arab', Jurnal Tarbiyatuna, 3 (2018), 39

Sholehuddin, Ach., 'Implementasi Metode Amtsilati Dalam Meningkatkan Kemampuan Maharah Qira'ah' Jurnal', Jurnal Arabiyatuna, 3 (2019), 48

Sternberg, Psikologi Kognitif (Yogyakarta: Pustaka Belajar, 2008)

Syah, Muhibbin, Pesikologi Belajar (Jakarta: PT Raja Grafindo Persada, 2012)

Wijaya, E.K, 'Pemanfaatan Modul Mnemonik (Modul Ingatan) Dalam Pembelajaran Program Paket C Untuk Meningkatkan Hasil Belajar', Jurnal Pendidikan Luar Sekolah, 5 (2012), 11

Zainudin, Ahmad, and Khozinul Asror, 'Metode Mnemonic: Solusi Kreatif Untuk Meningkatkan Pemahaman Nahwu Bagi Mahasiswa', in Sminar Nasional, 2019, p. 1 